Wellman, B.

1981 "The Community Question." American Journal of Sociology 84:1201-31.
SOME CONSIDERATIONS IN INTERVIEWING THE OLD, OLD

\author{
C. Ray Wingrove \\ University of Richmond
}

Mid-American Review of Sociology, 1987, Vol. XII, No. 2:71-76

Drawing upon personal experiences, the author makes a number of suggestions to follow when interviewing those in their late seventies and above. He deals with such topics as pitfalls in obtaining interviews, dress, rapport, length of interview, allaying respondents' fears, and coping with communication problems caused by interviewees' visual and hearing losses.

Some writers have pointed out recently that by emphasizing special characteristics and needs of the aged, gerontologists have unwittingly contributed to negative stereotypes and segregation of the old in this country (Kalish, 1979). With this in mind, I hesitate to single out a sub-category of the elderly as worthy of special consideration in the interview process. After all, should not the same general principles and guidelines of good interviewing be applied regardless of the age of the interviewee? The answer, of course, is "yes." But experiences over the years in interviewing subjects of all ages ranging from a nine year old fourth grader in rural Georgia to a 99 year old retired judge in Virginia, have sensitized me to the fact that there are some exceptional circumstances which cannot be ignored when dealing with certain age cohorts. I find this to be especially true when working with those whom professionals now refer to as the old, old or more specifically those 75 and over (Hendricks and Hendricks, 1986:40).

\section{OBTAINING THE INTERVIEW}

In spite of the prevalent assumption that older adults welcome interviews because they are bored, lonely, and have nothing to do, obtaining cooperation from subjects of any age for a lengthy interview is not easy. The researcher must convince the interviewee of the importance of the project and his or her part in it. Time must be found which does not infringe unduly upon busy schedules. Rapport must be established (see section on Rapport and Length of Interview) and confidentiality of responses guaranteed to the subject's satisfaction. However, an additional barrier surrounds the old, old, i.e., the one erected by those who protect 
them from outsiders. Whether administrators of housing for the aged, family members, friends, physicians, or clergy, there are numerous people who stand as buffers between the older respondent and the researcher. Everyone wants to know what is being investigated, for what purpose, and what questions are being asked. No one wants the older person to be upset or to be exploited. Such concern is admirable, but one of ten cannot help but wonder who or what is being protected - the aged respondent or the reputations of the protectors. After all, "Who knows what he or she is going to say?" This means that in addition to clearance by the University's Human Rights Committee, one must also be cleared through housing administrators, families, and sometimes other prof essionals.

Institutional representatives will demand their approval of all research instruments. Families may make the same request, which, of course cannot be honored. Exposure of the interview instrument to family members can result in serious biases as the respondent may then be rehearsed for the interview. Reassure concerned family members that the questions have been approved by a Human Rights Committee. Point out other studies which you might have done among the aged and encourage them to check you out with reputable references in the community. This will necessitate appraising one's colleagues, staff, community agencies and a variety of professionals of one's activities and warning them to be prepared for unsolicited calls regarding your character and integrity. ${ }^{1}$

\section{ATTENTION TO DRESS}

Arrive for the interview appropriately dressed. When interviewing the aged, this means be dressed up. A man should wear a coat and tie. Shoes should be shined, face clean shaven (or beard neatly trimmed), and hair well kept. Women should be comparably dressed and groomed. She should present herself as one might in business or in attending church. Certainly a tailored suit or dress with conservative accessories would be appropriate. A moderate amount of make up and neat coiffure are also recommended. Older people regardless of social class background are of a generation when representatives of universities, agencies, and other organizations simply did not dress casually when conducting business. And they will be dressed to receive the interviewer. Perhaps this is recognition of the esteem in which the university or organization is held which the researcher represents. It is rare that one will enter the home of an elderly person for an interview and not find both respondent and home neat and in readiness for a guest.

\section{ALLAY FEARS}

Many of the very old, especially women, live alone. Most are concerned about being victimized. This is understandable in view of the attention paid to crimes against the elderly and the exaggeration of statistics in this area. The researcher must be aware of these concerns and do whatever necessary to allay them. It is advisable to make a reminder call the day of the interview to confirm time and place, and to let the subject know what one looks like, how he or she will be dressed, and the intended mode of transportation. Then be on time! This will reinforce that one really is who he or she claims to be because he or she is there exactly when promised. It also lets older persons know that their time is not taken for granted. One should call if delayed - even if just for minutes. I have been called on the carpet - and rightfully so - for being just 5 minutes behind schedule.

\section{RAPPORT AND LENGTH OF INTERVIEW}

One should follow whatever standard and usual procedures work for him or her in establishing good rapport. However, in working with the aged, it is of ten wise at the onset to inquire about their pre-retirement years whether such inquiry is part of the formal interview schedule or not. This allows respondents to establish their worth in terms of contributions valued by society and it creates an excellent opportunity for exchange of comments between interviewer and interviewee. Often this kind of discussion will flow quite naturally into the interview itself. Another good ice breaker is to ask about some object in the respondent's environment - a piece of furniture, a painting, or perhaps a rug - which catches one's eye. Usually the old are surrounded by a lifetime of collections, and many welcome the opportunity to share with a truly interested person memories associated with them.

One should schedule ample time between appointments as interviews with the elderly tend to run longer than with younger subjects. After all they have lived longer, had more experiences and more time to develop ideas about a variety of topics and interests. Even a simple question such as "How old are you?" or "When were you born?" can trigger a lengthy response. Unless the response is totally irrelevant, hear the person out. Much useful 
information may be gained by listening. On one occasion when asked her age or birth date, a respondent rushed to find a huge memory album presented to her by her children and grandchildren on her recent birthday. It took at least twenty minutes to leaf through the album with her, but in so doing one learned more about her family relationships and interactions than would otherwise have been possible.

A good rule to follow is to let the respondent know approximately how long it takes most people to answer the questions, and then be prepared to stay longer. The old, old are likely to have been in retirement for a number of years and to have settled into a routine less hectic than the one followed in earlier life. This does not mean that time is of no consequence to them. Indeed time may be more precious than ever. It does mean that they probably plan fewer activities per day and are accustomed to allowing more time for each than they did when they were younger. It has been my experience in many instances that the interview becomes the primary activity planned for the day. Certainly one should keep an eye on the clock and ask the respondent if there is danger of infringing upon another of his or her appointments. If such is not the case, sit back and en joy!

\section{CONSIDERATION OF VISUAL AND HEARING LOSSES}

Woodruff and Birren (1983:251) remind us that some old people manifest so few age related changes that society continues to categorize them as young, and Robert Atchley (1980:109) points out that the variability in health status of older people is so extreme that poor health is by no means necessarily associated with aging. Certainly then it is naive to assume that all old people are sick or plagued by physical limitations. Nevertheless, it is well known that a majority of the old do have one or more chronic conditions. This figure is usually set at $85-86$ percent of the population 65 and over (Atchley, 1985:76), and the percentage rises with advanced age. The greater prevalence of certain of these physical declines among the very old should be remembered when interviewing them. It is likely, for example, that anyone approaching his or her eighties has suffered some loss of hearing and visual acuity. In many cases the losses may be significant even with partial corrections by mechanical devices (Cox, 1984:89).

Loss of hearing is of ten so gradual that many old people are unaware of the extent of their losses. Over the years they have learned to compensate by learning to read lips. Therefore, the researcher should look directly at the respondent while speaking.
Lip movement need not be exaggerated and the voice need not be raised unless so requested by the respondent. Experts warn us not to memorize interview schedules (Babbie, 1973:174); however, under these circumstances, one should become so familiar with the wording of questions that a glance at the first few words of each is all that is needed to trigger complete recall. This allows one to keep the head raised and the face in full view whenever addressing an interview subject. Of course, this assumes that the respondent can actually see the face clearly when it is in the line of vision. Remembering that some old people have visual as well as hearing losses, the interviewer should position him or herself in such a way that the light falls on his or her face during the interview. This means sitting opposite a window or very near a light. These actions can be carried out unobtrusively without causing embarrassment to any of the involved parties. If they prove necessary in a given situation, nothing is lost and unsuspecting subjects need not know they transpired.

Age related sensory changes may also necessitate sitting or standing closer to the older person than is normally comfortable for Americans. Interaction with the old, old suffering from multiple sensory losses may require spatial communication usually reserved for intimacy. Delong (1970) has pointed out that the elderly of ten interpret normal social distance as cool and rejecting. Therefore, try to avoid retreating on those occasions when the subject closes in and invades the interviewer's personal space.

\section{CONCLUDING COMMENTS}

If followed, these few suggestions should help in conducting a smooth interview with older individuals. Their execution does not involve complicated skills but simply a little extra time and a little extra attention to a special population. Other considerations, of course, may be called for in any particular case. Awareness of such likelihood and sensitivity to the needs and concerns of others will dictate what those considerations should be in each circumstance.

Rewards generally exceed any inconvenience associated with interviewing the very old. Rarely will one leave after an hour or an hour and a half of listening to an older person without a new sense of respect for the old - a respect for their achievements, their accumulated experiences and knowledge, and their worth as continuing reservoirs of our culture and heritage. Those who await their first such experience have a real treat in store for them. 


\section{FOOTNOTES}

1. For additional discussion on "Obtaining the Interview" see "Interviewer Characteristics and Success in Obtaining Consent," an unpublished paper by Rebecca G. Adams, Department of Sociology, UNC at Greensboro, NC 27412.

\section{REFERENCES}

Atchley, Robert C

1980 The Social Forces in Later Life. Third Edition. Belmont, CA: Wadsworth Publishing Company.

1985 Social Forces and Aging. Fourth Edition. Belmont, CA: Wadsworth Publishing Company.

Babbie, Earl R.

1973 Survey Research Methods. Belmont, CA: Wadsworth Publishing Company.

\section{Cox, Harold}

1984 Later Life: The Realities of Aging. Englewood Cliffs, NJ: Prentice-Hall, Inc.

Delong, A.J.

1970 "The Microspatial Structure of the Older Person." In L.A Pastalan and D.H. Carson (eds.), The Spatial Behavior of Older People. Ann Arbor, MI: Institute of Gerontology, University of Michigan.

Hendricks, Jon and C. Davis Hendricks

1986 Aging In Mass Society: Myths \& Realities. Third Edition. Boston, MA: Little, Brown and Company.

Kalish, Richard A.

1979 "The New Ageism and the Failure Models: A Polemic." The Gerontologist 19:398-402.

Woodruff, Diane S. and James E. Birren

1983 Aging: Scientific Perspectives and Social Issues. Second Edition. Monterey, CA: Brooks/Cole Publishing.

\section{BOOK REVIEWS}

Karl A. Peter, The Dynamics of Hutterite Society: An Analytic Approach. University of Alberta (dist. by Nebraska), 1987, 232 pp., 27.50 (cloth), 16.95 (paper)

While several scholars have written excellent books and articles on the Hutterite society, most notably John Hostetler (1974) and John Bennett (1967), these writings have been fundamentally descriptive in nature with little attempt to of fer strong theoretical models to explain the "whys" and "hows" of the Hutterite social structure. In The Dynamics of Hutterite Society, Karl Peter presents what is perhaps the first, full analytical discussion of the Hutterite sect and does so in a way that is, for the most part, highly readable and informative. Most of the thirteen chapters of this book were compiled from articles written over the years by the author or coauthored with colleagues and published in various journals. However, the author notes in the "Acknowledgments" section of the book that all the articles were revised and updated for this volume. The chapters cover a wide range of Hutterian society and history, though to some readers unfamiliar with the Hutterites, the chapters' organization may seem disjointed and some even perhaps too theoretical (especially Chapter 1). The novice reader or the undergraduate student could possibly appreciate more the scholarship and scope of the author in the Dynamics of Hutterite Society by reading beforehand several purely descriptive articles or books on the sect written by other authors (see references).

To analyze the Hutterites social structure, Karl Peter utilizes the theoretical model of Rosabeth Kanter in her studies of nineteenth century utopian movements and the theories of Max Weber and his concepts of "traditional authority" and "elective affinity" within a Gemeinschaft typology. Kanter postulates that commitment to a sect can be understood by applying a cost-benefit analysis. Through a highly structured socialization process within the sect and by various group pressures the members come to see their self-interest and the needs of the community as one. The members of the sect also assess the cost of leaving the group and increasingly view any benefits derived from joining the larger society as meaningless. Coupled with Max Weber's "traditional authority" and "elective affinity" which impose an order based on the absolute sanctity of the group's beliefs and the legitimacy of group control over the individual, the sect then successfully controls the mental orientation of the member who might otherwise critically question self and group. Peter suggests that Kanter's and 
Weber's theories can then account for why the Hutterite society has endured for 450 years in inhospitable social climates in both Europe and North America.

Kanter's theories on cost-benefit might explain membership in short-lived utopian groups, but for the Hutterites with their long history of endurance and struggle a cost-benefit model can only partially explain the Hutterite's success. Peter does not consider the cohesiveness and survival of the sect as primarily the result of external pressures. Instead, he dwells mostly on the internal dynamics of the group for his explanatory propositions. The solidarity of a group, as Durkheim has pointed out, is of ten partially a product of out-group rejection and hostility, whether real or imagined, which a group like the Hutterites has experienced for centuries. Would the Hutterite society have survived over the centuries if instead of undergoing persecution and rejection from various out-groups they had been more readily accepted and emulated by their neighbors?

Another external factor which should be considered in explaining why the Hutterites have endured over the centuries is how the availability of inexpensive land and receptive government policies has influenced the survival of the sect. The two most recent mass migrations of Hutterites to other countries, the 1870's migration of Hutterites from Russia to South Dakota and the 1918 trek from South Dakota to Canada, were only achieved because of the availability of fertile, inexpensive land and a favorable political climate in the new host country. What would have happened to the Hutterite social structure, in both the 1870's and during World War I when it was undergoing external pressures to change its fundamental ways of life, if a combination of lowpriced land and initial political acceptance had not been forthcoming from other countries?

While the theoretical orientations of the author pose some questions, the bulk of the book presents a highly stimulating excursion into the many areas of Hutterite society. The author in Part One addresses the religion and history of the Hutterites with a strong chapter on defection of sect members. Part Two encompasses a thorough discussion of such topics as family and community relations, childhood socialization and problems within the family structure. The author also presents an interesting view of the influences of continual inbreeding within the sect. In Part Three, Peter offers three chapters which discuss the Hutterites changing attitudes and practices regarding property and the restructuring of the Hutterite economic order; he closes with a provocative chapter on the changing roles of Hutterite women. In
Part Five, the last section of the book, the author looks at the changing attitudes of the Canadian government over the years towards the Hutterites and presents a critical discussion of the need for informed sect leadership and flexibility of the Hutterite population as the group confronts change from within and from pressures brought by the larger society.

For an individual who has viewed the Hutterites and related sects, such as the Amish, as possessing a relatively static, rigid social order, this book presents the Hutterites as a dynamic, constantly changing social structure blending and adapting ove the centuries to numerous social and political pressures from the larger society. The Dynamics of Hutterite Society will be a valuable asset to the specialists in their studies of utopian groups and sects, but the book can also be a valuable resource for generalists in their attempts to understand the broader society. The content of this book demands comparison to the larger social structure. For the hundred or so flourishing colonies in America one can pose the question: "How are the Hutterites able to maintain such remarkable harmony and order within a country (America) which has among the highest violent crimes, drug usage, marita instability, and mental illness rates of any country in the world?" What can America's politicians, educators and clergy learn from groups like the Hutterites which these leaders can utilize to help build and maintain a sense of harmony and order throughout the larger American society?

Karl Peter is to be commended for sound scholarship and for advancing knowledge about a unique sect which previously has received little analytical attention. This book should also provoke discussion and insight about the larger society, and for those reasons it is recommended reading for both academicians and upper-division students.

Grandview College

Douglas W. Kachel

\section{REFERENCES}

Bennett, J.

1967 Hutterian Brethren: The Agricultural Economy and Social Organization of a Communal People. Stanford: Stanford University Press. 
Hostetler, J.

1974 Hutterite Society. Baltimore: The John Hopkins University Press.

\section{Kachel, D.}

1987 "The Survival of the Hutterite Brethren Communes". The Ethnic Reporter, (Fall):1-5.
Arthur Stinchcombe, Economic Sociology. Orlando: Academic Press, 1983, 269 Pp., $\$ 12.95$

Stinchcombe sets for himself the major task of developing a macroscopic sociology of the economy. He does this by focusing on the enterprise, the individual productive unit. It is through the actions of the individual enterprises that the overall economic structure of society is generated. The focus of the book is on the forces that shape the actions of the individual enterprise.

These forces include ecological and technological factors which constitute the "forces of production". These interact with the "structures of incentives" for capitalists and workers which constitute the "relations of production". These latter factors involve the social structures required to allocate resources and people necessary for an economically productive system. The economic structure composed of similar "relations of production" and "forces of production" constitutes a characteristic "mode of production", a concept rooted in the individual enterprise.

Stinchcombe argues that this approach is based on Marx's original analysis. He believes that Neo-Marxists have strayed from the original strength of Marx by focusing on the social impacts of economic activities without an adequate understanding of the economic activities themselves. He says that "the shaping of society and politics by the economy cannot be properly analyzed without a good analysis of the economy". His goal, a lofty one indeed, is "to outline and illustrate the economic sociology required to complete and unify the Neo-Marxist tradition".

$\mathrm{He}$ is only partially successful in achieving his goal. He does an admirable job in refocusing attention on the enterprise as the basic unit of economic analysis and the forces that shape the actions of these basic units. However, he is less successful in developing a theoretical connection between the individual firm and the overall economy and how the resulting economy shapes society and politics.

Stinchcombe illustrates the components of his thesis by applying them to three different cultures at different stages of development. These are the Karimojong a primitive herding society; eighteenth century France, characterized as a late feudal or early capitalist society; and the U.S., a modern industrial capitalist society. Although these case studies are useful for illustrating the effect of different forces on the enterprise, in the absence of a coherent theory connecting the enterprise to the overall economy and society they are only suggestive of these kinds of macro connections. 